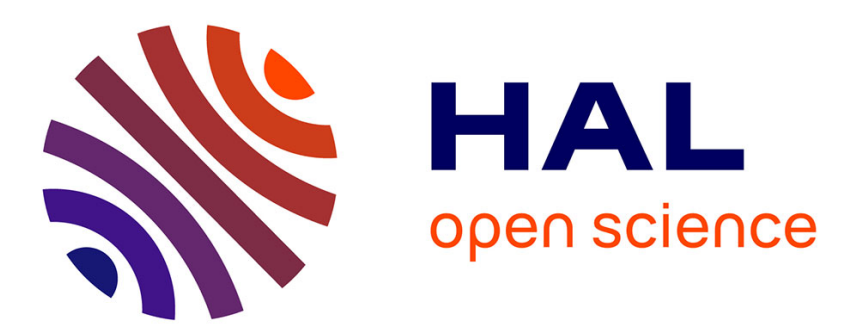

\title{
Adaptive psychopathic traits: positive outcomes in a college student sample
}

Jonathan Bronchain, Henri Chabrol, Patrick Raynal

\section{To cite this version:}

Jonathan Bronchain, Henri Chabrol, Patrick Raynal. Adaptive psychopathic traits : positive outcomes in a college student sample. Current Psychology, 2019, 40, pp.4997-5004. 10.1007/s12144-019-004343. hal-03201617

\section{HAL Id: hal-03201617 \\ https://hal-univ-tlse2.archives-ouvertes.fr/hal-03201617}

Submitted on 19 Apr 2021

HAL is a multi-disciplinary open access archive for the deposit and dissemination of scientific research documents, whether they are published or not. The documents may come from teaching and research institutions in France or abroad, or from public or private research centers.
L'archive ouverte pluridisciplinaire HAL, est destinée au dépôt et à la diffusion de documents scientifiques de niveau recherche, publiés ou non, émanant des établissements d'enseignement et de recherche français ou étrangers, des laboratoires publics ou privés. 
Adaptive psychopathic traits: Positive outcomes in a college student sample

Jonathan Bronchain, Henri Chabrol, \& Patrick Raynal

Centre d'Etudes et de Recherches en Psychopathologie et Psychologie de la Santé, Université de Toulouse, France

Author Note

Correspondence concerning this article should be addressed to: Jonathan Bronchain, UFR de Psychologie, Université de Toulouse-Jean Jaurès, 5 allées Antonio Machado, 31058 Toulouse cedex 9. E-mail address: jonathan.bronchain@etu.univ-tlse2.fr. Tel: +33781533109. 


\begin{abstract}
The presence of positive outcomes observed in some individuals with high psychopathic traits remains relatively unexplained. This study aimed at examining the contribution of specific adaptive psychopathic traits to the emergence of positive behavioral and psychopathological consequences. Participants were 2291 French college students who completed self-report questionnaires assessing negative and adaptive psychopathic traits and psychopathological variables. A cluster analysis based on the negative and adaptive psychopathic traits total scores yielded four distinct groups characterized by moderate negative traits and low adaptive traits (moderate negative psychopathic traits cluster; NP), low negative and adaptive traits (low traits cluster; LT), low negative traits and moderate adaptive traits (adaptive psychopathic traits cluster; AP) and high negative and adaptive traits (high traits cluster; HT). Comparisons between clusters suggested that adaptive psychopathic traits were associated with decreased levels of perceived stress, depression and suicidal ideation. However, the frequency of prosocial and antisocial behaviors was not affected by the presence of adaptive traits. Our results provide important information for assessment and treatment of the negative consequences of psychopathic traits.
\end{abstract}

Keywords: psychopathic traits; depressive symptoms; suicidal ideation; perceived stress; antisocial behavior; prosocial behavior 


\section{Introduction}

Psychopathy has been classically described as a severe personality disorder and a unitary construct associated with a variety of affective, behavioral and interpersonal impairments (Cleckley 1941). However, and despite an absence of agreement, current research tends to define psychopathy as a dimension of personality consisting of traits such as interpersonal antagonism, narcissism, emotional stability, and inhibitory control deficiency (Lynam et al. 2011). Since these traits do not demonstrate a systematic strong association, there is disagreement regarding whether psychopathy is a classical syndrome, with a uniform set of traits, or a multifaceted syndrome related to various profiles and consequences (Lilienfeld et al. 2014). Furthermore, the specific arrangement of these traits, and their reciprocal weight, would foster the emergence of positive or negative outcomes (e.g., Mullins-Sweatt et al. 2010).

Nevertheless, psychopathic traits have been extensively studied in association with the deleterious consequences that they could engender. The study of forensic and psychiatric samples and the preferred assessment tools (semi-structured interview for diagnostic purposes) favored the association of psychopathy with negative outcomes (Lilienfeld et al. 2014). However, the emergence of self-reported questionnaires, the community sample evaluation and the connexion with general personality literature have brought new elements essential to understand this atypical syndrome (Fowler \& Lilienfeld, 2013; Lynam et al. 2018; Sellbom et al. 2018).

Thus, current research tends to demonstrate that psychopathy can be associated with adaptive social functioning. Successful psychopathy (Hall \& Benning 2006) is a variant of psychopathic personality disorder characterized by the presence of individual successes and a high psychosocial adaptation. Moreover, several adaptive traits such as leadership, logical thinking, composure, creativity, fearlessness, money smart, focus, extroversion, and 
management have been associated with psychopathic traits and could contribute to a positive adjustment within a set environment (Durand 2017). An important body of literature supports the existence of psychopathy variants in college students (e.g., Falkenbach, Stern, \& Creevy, 2014) which can be differentiated by anxiety, borderline and narcissistic traits levels. Data in this field warrant directing research towards heterogeneous personality profiles.

As a result, three main models have attempted to explain the emergence conditions of positive outcomes related to psychopathic personality traits (Hall \& Benning 2006). First, the differential-severity model conceptualizes successful psychopathy as an attenuated expression of psychopathic personality disorder. Psychopathy would be a unitary construct and its manifestations would vary only according to its intensity. Second, for the moderatedexpression model, successful psychopathy would be an atypical manifestation of psychopathy moderated by independent structural, environmental and contextual protective factors (Steinert et al. 2017). Third, the differential-configuration model presumes that successful and unsuccessful psychopaths would differ in their core psychopathic traits configuration (Lilienfeld et al. 2015). Unlike the two previous models, this one assumes that psychopathy is a multidimensional construct and that the singular combination of psychopathic traits can lead to varied consequences.

The ability of high psychopathic traits individuals to experience negative affects seems to be related to these different combinations of traits. Current evidence highlights the beneficial effect of interpersonal psychopathic traits, such as callous- unemotional traits, fearlessness, and narcissism, against the development of stress and anxiety symptoms (Derefinko 2015; Durand \& Plata, 2017; Kauten et al. 2013). Interpersonal and affective psychopathic traits would also be protective factors against the development of post-traumatic stress symptoms (e.g., Anestis et al. 2017). 
In contrast, relationships between psychopathic personality traits and depressive symptoms have been poorly studied in community samples. Although impulsivity, callous, and narcissistic traits are sometimes considered defenses against depressed mood (Chabrol et al. 2010), some studies reported a negative link, or an absence of connection, between psychopathy and depressive symptoms in youth (e.g., Chabrol et al. 2009). At the same time, if Cleckley (1941) evoked a form of immunity to suicide in his first descriptions of psychopathy, more recent data nuanced this point (Anestis et al. 2016; Chabrol \& SaintMartin 2009; Douglas et al. 2006). In particular, impulsivity and antisociality were positively associated with suicidal ideation, suicidal attempts, and self-harm behaviors in young adults, whereas callous- unemotional traits and interpersonal factors related to psychopathy showed a negative association or no association with these same variables (Conner et al. 2004; Harrop et al. 2017; Javdani et al. 2011; Verona et al. 2012).

Regarding behavioral outcomes, psychopathic personality traits seem to predict antisociality, aggression and externalizing behaviors in adolescents (e.g., Chabrol et al. 2009) and young adults (e.g., Hecht et al. 2016). However, yet again, a person-centered approach seems to be relevant. Hostility traits and disinhibition showed positive associations with antisocial behavior (Lynam et al. 2011), while emotional stability factor showed no significant association with this variable (Siegfried-Spellar et al. 2017; Lynam \& Miller 2012; Miller \& Lynam 2012). In addition, recent studies demonstrated that the interaction among the interpersonal, affective, and behavioral factors of youth psychopathy provide incremental information in predicting self-reported delinquency and conduct disorder symptoms (Fanti et al. 2018; Somma et al. 2018).

Unexpectedly, prosocial behaviors do not necessarily display a negative association with antisocial behaviors and psychopathic traits. Prosocial behaviors would be conditioned by multiple factors such as empathy and the public or anonymous nature of the behavior 
(Eisenberg et al. 2010; McGinley \& Carlo 2006). Therefore, prosocial behaviors and psychopathic personality traits displayed complex relationships. Public prosocial behaviors have been shown to be positively associated with callous-unemotional traits and egocentricity, and negatively associated with the social deviance factor of psychopathy (White 2014).

Consequently, psychopathy seems to be an atypical syndrome that could vary in its expression and lead to different consequences. That is why it is necessary to aim for a comprehensive assessment of psychopathic traits in a person-centered approach. In line with the differential-configuration model, this approach assumes that psychopathy includes several dimensions that can differently co-occur, allowing to identify distinct classes of individuals characterized by different profiles of psychopathic traits. To our knowledge, there is no study linking profiles based on adaptive and maladaptive components of psychopathy to the psychopathological consequences most frequently found in college students. An accurate understanding of these profiles may help to better target the treatment of youth displaying these characteristics.

Starting from these considerations, the present study aimed to test the differentialconfiguration model. We defined homogeneous groups of participants using cluster analysis and evaluated the relative contribution of negative and adaptive psychopathic traits on antisocial and prosocial behaviors, depressive symptoms, suicidal ideation, and perceived stress. We hypothesized that (1) individuals with high psychopathic traits could demonstrate high psychosocial adaptation and that (2) the emergence of these positive outcomes would be related to the level of adaptive psychopathic traits.

\section{Method}

\section{Participants and procedures}

The data were collected through an online survey that was distributed to students from public French universities. A message presenting the objectives of the study was shared on 
social media networks in working groups specifically dedicated to students. This message contained a link to a Qualtrics@ form. The final sample consisted of 2291 young adults (737 males, $32 \%$; 1554 females, $68 \%$ ) of which $8 \%$ of the data were previously excluded. These data included outliers and respondents not meeting inclusion criteria (i.e., being a college student in a French university and aged between 18 and 28). Participants ranged in age from 18 to 28 years old $(M=19.9 \pm 1.95)$. Regarding the education domain of the participants, $31 \%$ were students in medical and paramedical courses, $13 \%$ in human sciences, $11 \%$ in science, engineering, $8 \%$ in law, $8 \%$ in economics, commerce, management and communication, $5 \%$ in letters, $5 \%$ in education and pedagogy, $4 \%$ in history, geography, political science, $1 \%$ in art and design, $1 \%$ in art history and archaeology, $0.48 \%$ in philosophy and $13 \%$ were students in another field. The objectives of the study were presented to all participants at the beginning of the online questionnaire, specifying that this was a study on personality and behaviors. The participants were assured of the anonymity of their answers. Participants' personal identifiers (names, student ID numbers, email addresses, IP addresses) were not collected. The demographic data collected were age, gender, field and level of study, and nationality. The study followed the guidelines of the Helsinki declaration. Ethical issues of the current research were explored at a research meeting.

Measures

Psychopathic traits were assessed using The Elemental Psychopathy Assessment-Short Form (EPA-SF; Lynam et al. 2013) is an 72-item inventory, rated on a 5-point scale, that assesses 18 traits (with 4 items each) identified as descriptive of psychopathy (e.g., "Feeling sorry for others is a sign of weakness"). These 18 traits can be combined into a total score or used to score four factors: Interpersonal Antagonism, Emotional Stability, Disinhibition, and Narcissism. 
Adaptive psychopathic traits were assessed using Durand Adaptive Psychopathic Traits Questionnaire (DAPTQ; Durand 2017). The DAPTQ is a 41-item self-reported questionnaire, rated on a 6-point scale, which provides a total score along 9 subscales scores: Leadership, Logical Thinking, Composure, Creativity, Fearlessness, Money Smart, Focus, Extroversion, and Management (e.g., "I can effortlessly mingle with any group"). A higher score represents higher adaptive traits.

Antisocial behavior was measured using the aggregated items of different scales: The Subtypes of Antisocial Behavior Questionnaire (STAB-Q; Burt \& Donnellan, 2009), The Self-Report Delinquent Behaviour (Leenders \& Brugman, 2005), the French version of the Antisocial Behavior Scale (ABS; Schwab-Stone et al. 1999), the Self-Reported Delinquency Behavior (SRDB; Elliott \& Menard 1996), and questions from the National Youth Survey (Elliott et al. 1987), the Self-Reported Delinquency Survey (Elliot \& Ageton 1980) and the Sexual Experiences Survey (Koss \& Oros, 1982). The final questionnaire reported 50 items referring to antisocial behaviors in college students such as disrespect of parental rules, disrespect of social rules, disrespect of university rules, substance use, road delinquency, vandalism, stealing, interpersonal aggression, bullying, cyberbullying, sexism and gender harassment, sexual delinquency, and dating violence. Respondents were asked to report on a 5-point scale how many times they had been involved in these 50 antisocial behaviors during the past year (e.g., "Insult your partner").

Prosocial behavior was assessed using the Prosocial Behaviour Scale (PBS; Caprara \& Pastorelli, 1993; Goutaudier et al. 2015). The PBS is a 16-item self-reported questionnaire, rated on a 5-point scale (e.g., "I try to make sad people happier").

Perceived stress in the last month was measured using the Perceived Stress Scale (PSS; Cohen et al. 1983; Lesage et al. 2012). The PSS is a self-report measure consisting of 
10 items rated on a 5-point scale (e.g., "How often have you found that you could not cope with all the things that you had to do").

Depressive symptoms were assessed using the Patient Health Questionnaire-9 (PHQ9; Kroenke et al. 2001; Carballeira et al. 2007). The PHQ-9 is composed of 9 items on a 4point scale (e.g., "Little interest or pleasure in doing things").

Suicidal ideation during the past week was assessed with a 3-item self-reported questionnaire rated on a 4-point scale (Garrison et al. 1991).

Cronbach's $\alpha$ for all variables are reported in Table 1 .

\section{Statistical analysis}

A cluster analysis was performed to identify distinct profiles of participants based on their standardized total scores for EPA-SF and DAPTQ. A hierarchical cluster analysis was then conducted (Ward's method with Euclidean distance). The dendrogram and the agglomeration schedule were used to identify the number of clusters. Then, K-means clustering was used to assign each individual to the identified clusters. Statistical analyses were performed using Statistica 10.

\section{Results}

\section{Descriptive statistics}

Means and standard deviations for all variables are reported in Table 1.

\section{Cluster analysis}

Based both on the dendrogram and on the aggregation curve, a four-cluster solution was identified. The dendrogram is presented in Figure 1. The agglomeration schedule showed a sudden increase in linkage distance which more than doubled when four clusters merged to three clusters (from 146.07 to 404.40). This indicated that the passage from four to three clusters would have more impact on the heterogeneity of the clusters than previous stages of the analysis. Therefore, the four-cluster solution was the most appropriate (Figure 2). A 
discriminant analysis showed clear differences between the four clusters (Wilks' $\lambda=0.12, p<$ 0.0001 ) with $97.1 \%$ of original cases correctly classified.

The first group $(\mathrm{n}=568$ [25\%], women $74 \%$, men $26 \%)$ was called the moderate negative psychopathic traits cluster cluster (NP) because it was characterized by students with average negative psychopathy scores greater than half a standard deviation, and lower adaptive psychopathic traits scores of one-half standard deviation to the means of the total sample (Table 1). The second group $(\mathrm{n}=603$ [28\%], women 84\%, men $16 \%)$ included participants with negative and adaptive psychopathic traits scores lower than the mean of the total sample by at least half a standard deviation and was therefore the Low Traits cluster (LT). The third group $(\mathrm{n}=678$ [30\%], women 62\%, men 38\%), named the Adaptive Psychopathic traits cluster (AP), consisted of individuals demonstrating, on the one hand, average negative psychopathy scores and, on the other hand, higher adaptive trait scores onehalf standard deviation to the means of the total sample. Finally, the fourth group $(n=442$ [19\%], women $46 \%$, men 54\%) was called the high traits cluster (HT) because it was characterized by participants with negative and adaptive psychopathic traits scores greater than the average of the total sample of more than one standard deviation.

We then compared these clusters on the depressive symptoms, the suicidal ideation, the perceived stress and the prosocial and antisocial behavior using ANOVA and Tukey HSD post-hoc test. These comparisons revealed that the HT and AP groups demonstrated significantly fewer depressive symptoms and suicidal ideation than the LT and NP groups. In addition, HT and AP clusters had significantly lower scores of perceived stress than the other two groups and did not differ between each other on this variable. Finally, the LT and AP clusters showed the highest levels of prosocial behavior and the lowest frequency of antisocial behavior. The comparison between these two clusters did not reveal any significant differences on these dimensions. The level of adaptive traits associated with psychopathy 
seems to differentiate clusters on perceived stress, depressive symptoms, and suicidal ideation relatively independently of the negative psychopathy score.

\section{Discussion}

Based on the evaluation of negative and adaptive psychopathic personality traits profiles and on cluster analysis, we identified four distinct groups of participants. These clusters were similar in size but displayed significant differences on their level of antisocial and prosocial behaviors, depressive symptoms, suicidal ideation, and perceived stress. We can note that $74 \%$ of the sample is included in clusters with at least moderate adaptive or negative psychopathic traits. Of note, the gender distribution in the four clusters support that psychopathy in college student could have a gender expression (e.g., Falkenbach, Reinhard, \& Larson, 2017). The higher the adaptive psychopathic traits in the cluster, the lower the proportion of women. The presence of these traits could therefore be explained by genetic factors, socio-cultural effects, or a combination of both. The social valuation of certain traits

(e.g., composure, fearlessness, leadership) could be gender-oriented and lead to individual variation in the configuration of psychopathic traits.

As expected, we identified a cluster with high psychopathic traits and an adaptive functioning on some psychopathological indicators (HT). Indeed, individuals in the HT cluster reported a significantly lower level of depressive symptoms, suicidal ideation, and perceived stress than the NP (moderate negative psychopathic traits only) and LT (low negative and adaptive psychopathic traits) clusters. The AP cluster was the one with the lowest scores on all the psychopathological indices evaluated. These findings complement the results of previous studies that have emphasized the negative association between psychopathic personality traits and suicidal ideation and anxious and depressive symptoms (e.g., Derefinko 2015; Verona et al. 2012). 
Our study also brings new information about the manifestations of psychopathy in college students. A significant minority of college students (19\%) displayed both high levels of negative and adaptive psychopathic traits. Interestingly, the level of adaptive psychopathic traits appears to be the variable that differentiates the four groups most distinctly, regardless of the level of psychopathy. These results confirm the relevance of the differentialconfiguration model (Lilienfeld et al. 2015). In this study, the specific arrangement of psychopathic personality traits, including highly adaptive traits, has been shown to regulate the emergence of negative outcomes. On the other hand, the level of negative psychopathic traits seems to be a reliable indicator of the increased frequency of antisocial behaviors and a deficit of prosocial behaviors. This relationship would not be affected by the presence of adaptive psychopathic traits. However, adaptive traits related to negative psychopathy could be protective of severe delinquent or criminal behaviors not evaluated in this study.

Finally, although the results obtained are data-driven, they raise concern about a possible increase of psychopathic traits in French college students. Indeed, the constant rise of individualism and narcissism in our Western societies (e.g., Twenge \& Foster 2008) tend to reward psychopathic tendencies that could favor individual successes (Irtelli \& Vincenti 2017). Therefore, it could be beneficial to consider whether psychopathic personality traits are much more common in recent generations.

\section{Limitations}

This study has several limitations. First, although internet data collection methods using online completion of self-report questionnaires from self-selected samples are consistent with findings from traditional methods (Gosling et al. 2004), the possibility that participant self-selection may have biased the results cannot be excluded. Moreover, the use of a self-report scale to assess psychopathic traits could be arguable, given the tendency to deception, manipulation, and lie observed in these individuals. Nevertheless, meta-analytic 
data showed that psychopathy scores were moderately and negatively associated with social desirability and faking good (Ray, Weir, Poythress, \& Rickelm, 2011). Self-report questionnaires are also consensually accepted as the best tools for assessing psychopathy in non-institutionalized samples (Sellbom et al., 2018). Second, the cross-sectional nature of the study limits our ability to make predictions about future behaviors or psychopathological consequences. Third, whether the results of the current study are applicable to older ageranges or other groups of young adults is unknown, since all participants were university students. Similarly, results may not generalize beyond the French population. Furthermore, they may not be applicable to populations from non-Westernized cultures and/or societies that emphasize collectivism rather than individualism.

\section{Implications and Future Directions}

Our results suggest the importance of a multidimensional assessment of psychopathic personality traits in young adults. Using a person-centered approach and evaluating adaptive psychopathic traits with measures specifically dedicated for this purpose, our study emphasized the importance of combining the adaptive and maladaptive components of psychopathy. Since the presence of adaptive traits is associated with various positive consequences, they may represent a potential treatment target to minimize the deleterious effects of some negative psychopathic personality traits on mental health and psychosocial adjustment. Non-institutionalized patients displaying high negative psychopathic traits could benefit from brief and effective treatments based on adaptive characteristics development. These interventions should become a priority for clinicians to reduce the contact of at-risk populations with legal services, improve their quality of life, and reduce the cost of potentially affected legal and medical services. However, although some of these traits have been qualified as adaptive, they could have negative consequences if they are used for manipulation and deception, especially in the workplace (Carre, Mueller, Schleicher, \& Jones, 
2018). So, it would be interesting to determine precisely the features that allow a positive adjustment without negative effects for the social environment.

To conclude, students with high psychopathic traits may not be likely to self-refer for health services, and schools do not have the resources to evaluate all students. In this context, it would be interesting to develop adaptive traits through implemented activities such as physical education for example. Indeed, specific intervention programs with physical education teachers have shown to reduce antisocial behavior and need frustration, and increase prosocial behavior among students (Cheona et al. 2018). Future research should lead to identify other structural, environmental and contextual factors responsible for positive and negative outcomes in individuals with high psychopathic traits.

\section{Declaration of conflicting interests}

On behalf of all authors, the corresponding author states that there is no conflict of interest.

\section{Funding}

The authors received no financial support for the research, authorship, and/or publication of this article.

\section{Ethical statement}

All procedures performed were in accordance with the ethical standards of the national research standards and with the 1964 Helsinki declaration and its later amendments. Informed consent was obtained from all individual participants included in the study. 


\section{References}

Anestis, J. C., Anestis, M. D., Rufino, K. A., Cramer, R. J., Miller, H., Khazem, L. R., \& Joiner, T. E. (2016). Understanding the relationship between suicidality and psychopathy: an examination of the interpersonal-psychological theory of suicidal behavior. Archives of Suicide Research, 20, 349-368. https://doi.org/10.1080/13811118.2015.1048399.

Anestis, J. C., Harrop, T. M., Green, B. A., \& Anestis, M. D. (2017). Psychopathic personality traits as protective factors against the development of post-traumatic stress disorder in a sample of National Guard combat veterans. Journal of Psychopathology \& Behavioral Assessment, 39, 220-229. https://doi.org/10.1007/s10862-017-9588-8.

Burt, S. A., \& Donnellan, M. B. (2009). Development and Validation of the Subtypes of Antisocial Behavior Questionnaire. Aggressive Behavior, 35, 376-398. https://doi.org/10.1002/ab.20314.

Caprara, G. V., \& Pastorelli, C. (1993). Early emotional instability, prosocial behaviour, and aggression: Some methodological aspects. European Journal of Personality, 7, 19-36. https://doi.org/10.1002/per.2410070103.

Carballeira, Y., Dumont, P., \& Borgacci, S. (2007). Criterion validity of the French version of Patient Health Questionnaire (PHQ) in a hospital department of internal medicine. Psychology Psychotherapy, 80, 69-77. https://doi.org/10.1348/147608306X103641.

Carre, J. R., Mueller, S. M., Schleicher, K. M., \& Jones, D. N. (2018). Psychopathy and deviant workplace behavior: A comparison of two psychopathy models. Journal of Personality Disorders, 32, 242-261.https://doi.org/10.1521/pedi_2017_31_296.

Chabrol, H., Labeyrie, N., Rodgers, R. F., \& Levenson, M. R. (2010). An exploratory study of the relations between psychopathic traits and depressive symptoms in a non-clinical 
sample of adolescents. Revue Européenne de Psychologie Appliquée, 60, 181-187. https://doi.org/10.1016/j.erap.2009.10.002.

Chabrol, H., \& Saint-Martin, C. (2009). Psychopathic traits and suicidal ideation in highschool students. Archives of Suicide Research, 13, 64-73. https://doi.org/10.1080/13811110802572155.

Chabrol, H., van Leeuwen, N., Rodgers, R., \& Séjourné, N. (2009). Contributions of psychopathic, narcissistic, machiavellian, and sadistic personality traits to juvenile delinquency. Personality and Individual Differences, 47, 734-739. https://doi.org/10.1016/j.paid.2009.06.020.

Cheon, S. H., Reeve, J., \& Ntoumanis, N. (2018). A needs-supportive intervention to help PE teachers enhance students' prosocial behavior and diminish antisocial behavior. Psychology of Sport and Exercise, 35, 74-88. https://doi.org/10.1016/j.psychsport.2017.11.010.

Cleckley, H. (1941). The mask of sanity: An attempt to reinterpret the so-called psychopathic personality (1st ed.). England: Oxford.

Cohen, S., Kamarck, T., \& Mermelstein, R. (1983). A global measure of perceived stress. Journal of Health and Social Behavior, 24, 385-396. https://doi.org/10.2307/2136404.

Conner, K. R., Meldrum, S., Wieczorek, W. F., Duberstein, P. R., \& Welte, J. W. (2004). The association of irritability and impulsivity with suicidal ideation among 15 - to 20 -yearold males. Suicide and Life-Threatening Behavior, 34, 363-373. https://doi.org/10.1521/suli.34.4.363.53745.

Derefinko, K. (2015). Psychopathy and low anxiety: Meta-analytic evidence for the absence of inhibition, not affect. Journal of Personality, 83, 693-709. https://doi.org/10.1111/jopy.12124. 
Douglas, K. S., Herbozo, S., Poythress, N. G., Belfrage, H., \& Edens, J. (2006). Psychopathy and suicide: A multisample investigation. Psychological Services, 3, 97-116. https://doi.org/0.1037/1541-1559.3.2.97.

Durand, G. (2017). The Durand Adaptive Psychopathic Traits Questionnaire: Development and Validation. Journal of Personality Assessment, 1-10. Advance online publication. https://doi.org/10.1080/00223891.2017.1372443.

Durand, G. \& Plata, E. M. (2017).The effects of psychopathic traits on fear of pain, anxiety, and stress. Personality and Individual Differences, 119, 198-203. https://doi.org/10.1016/j.paid.2017.07.024.

Eisenberg, N., Eggum, N. D., \& Di Giunta, L. (2010). Empathy related responding: Associations with prosocial behavior, aggression, and intergroup relations. Social Issues and Policy Review, 4, 143-180. https://doi.org/10.1111/j.17512409.2010.01020.x.

Elliott, D. S., \& Ageton, S. (1980). Reconciling ethnicity and class differences in self-reported and official estimates of delinquency. American Sociological Review, 45, 95-110. https://doi.org/10.2307/2095245.

Elliott, D. S., Dunford, F. W., \& Huizinga, D. H. (1987). The identification and prediction of career offenders utilizing self-reported and official data. In J. D. Burchard \& S. N. Burchard (Eds.), Prevention of delinquent behavior (pp. 90-121). Thousand Oaks, CA: Sage.

Elliott, D. S., \& Menard, S. (1996). Delinquent friends and delinquent behavior: Temporal and developmental patterns. In J. D. Hawkins (Ed.), Delinquency and crime: Current theories (pp. 28-67). Cambridge: Cambridge University Press. 
Falkenbach, D. M., Reinhard, E. E., \& Larson, F. R. R. (2017). Theory based gender differences in psychopathy subtypes. Personality and Individual Differences, 105, 16. https://doi.org/10.1016/j.paid.2016.09.023.

Falkenbach, D. M., Stern, S. B., \& Creevy, C. (2014). Psychopathy variants: Empirical evidence supporting a subtyping model in a community sample. Personality Disorders: Theory, Research, and Treatment, 5, 10. http://dx.doi.org/10.1037/per0000021.

Fanti, K. A., Kyranides, M. N., Lordos, A., Colins, O., \& Andershed, H. (2018). Unique and interactive associations of callous unemotional traits, impulsivity (DI) and narcissism (GM traits) with child and adolescent conduct disorder symptoms. Journal of Psychopathology and Behavioral Assessment. Advance online publication.

Fowler, K. A., \& Lilienfeld, S. O. (2013). Alternatives to the psychopathy checklist-revised. In K. A. Kiehl \& W. P. Sinnott-Armstrong (Eds.), Handbook of psychopathy and the law (pp. 34-60). NewYork: Oxford University Press.

Garrison, C. Z., Addy, C. L., Jackson, K. L., McKeown, R. E., \& Waller, J. L. (1991). A longitudinal study of suicidal ideation in young adolescents. Journal of the American Academy of Child and Adolescent Psychiatry, 30, 597-603. https://doi.org/10.1097/00004583-199107000-00011.

Gosling, S. D., Vazire, S., Srivastava, S., \& John, O. P. (2004). Should we trust Web-based studies? A comparative analysis of six preconceptions about Internet questionnaires. American Psychologist, 59, 93-104. https://doi.org/10.1037/0003-066X.59.2.9.

Goutaudier, N., Lopez, S., Belarbi, A., Ducroux, M., \& Chabrol, H. (2015). Traits de personnalité et comportements prosociaux chez les adolescents: Le rôle médiateur de l'empathie. Neuropsychiatrie de l'Enfance et de l'Adolescence, 63, 310-316. https://doi.org/10.1016/j.neurenf.2014.11.007. 
Hall, J. R., \& Benning, S. D. (2006). The "successful” psychopath. In C. J. Patrick (Ed.), Handbook of psychopathy (pp. 459-475). New York, NY: Guilford Press.

Harrop, T. M., Preston, O. C., Khazem, L. R., Anestis, M. D., Junearick, R., Green, B. A., \& Anestis, J. C. (2017). Dark traits and suicide: Associations between psychopathy, narcissism, and components of the interpersonal-psychological theory of suicide. Journal of Abnormal Psychology, 126, 928-938. https://doi.org/10.1037/abn0000300.

Hecht, L. K., Berg, J. M., Lilienfeld, S. O., \& Latzman, R. D. (2016). Parsing the heterogeneity of psychopathy and aggression: differential associations across dimensions and gender. Personality Disorders: Theory, Research, and Treatment, 7, 2-14. https://doi.org/10.1037/per0000128.

Irtelli, F., \& Vincenti, E. (2017). Successful Psychopaths: A Contemporary Phenomenon. In Psychopathy-New Updates on an Old Phenomenon. InTech. http://dx.doi.org/10.5772/intechopen.70731.

Javdani, S., Sadeh, N., \& Verona, E. (2011). Suicidality as a function of impulsivity, callousunemotional traits, and depressive symptoms in youth. Journal of Abnormal Psychology, 120, 400-413. https://doi.org/10.1037/a0021805.

Kauten, R., Barry, C. T., \& Leachman, L. (2013). Do perceived social stress and resilience influence the effects of psychopathy-linked narcissism and CU traits on adolescent aggression? Aggressive Behavior, 39, 381-390. https://doi.org/10.1002/ab.21483.

Koss, M. P., \& Oros, C. J. (1982). Sexual Experiences Survey: a research instrument investigating sexual aggression and victimization. Journal of Consulting and Clinical Psychology, 50, 455-457. https://doi.org/ 10.1037/0022-006X.50.3.455.

Kroenke, K., Spitzer R. L., \& Williams J. B. (2001). The PHQ-9: Validity of a brief depression severity measure. Journal General Internal Medicine, 16, 606-13. https://doi.org/10.1046/j.1525-1497.2001.016009606.x. 
Leenders, I., \& Brugman, D. (2005). Moral/non- moral domain shift in young adolescents in relation to delinquent behaviour. British Journal of Developmental Psychology, 23, 65-79. https://doi.org/10.1348/026151004X20676.

Lesage, F. X., Berjot, S., \& Deschamps, F. (2012). Psychometric properties of the French versions of the Perceived Stress Scale. International Journal of Occupational Medicine and Environmental Health, 25, 178-84. https://doi.org/10.2478/S13382-0120024-8.

Lilienfeld, S. O., Watts, A. L., Francis Smith, S., Berg, J. M., \& Latzman, R. D. (2014). Psychopathy deconstructed and reconstructed: Identifying and assembling the Personality building blocks of Cleckley’s chimera. Journal of Personality, 83, 593610. https://doi.org/10.1111/jopy.12118.

Lilienfeld, S. O., Watts, A. L., \& Smith, S. F. (2015). Successful psychopathy: A scientific status report. Current Directions in Psychological Science, 24, 298-303. https://doi.org/10.1177/0963721415580297.

Lynam, D. R., Gaughan, E. T., Miller, J. D., Miller, D. J., Mullins-Sweatt, S., \& Widiger, T. A. (2011). Assessing the basic traits associated with psychopathy: Development and validation of the Elemental Psychopathy Assessment. Psychological Assessment, 23, 108-124. https://doi.org/10.1037/a0021146.

Lynam, D. R., \& Miller, J. D. (2012). Fearless dominance and psychopathy: Response to Lilienfeld et al. Personality Disorders: Theory, Research, and Treatment. 3. Personality Disorders: Theory, Research, and Treatment (pp. 341-353). https://doi.org/10.1037/a0028296.

Lynam, D. R., Miller, J. D., \& Derefinko, K. J. (2018). Psychopathy and personality: An articulation of the benefits of a trait-based approach. In C.J. Patrick (Ed.), Handbook of Psychopathy (p. 259-280). New York: Guilford Press. 
Lynam, D. R., Sherman, E. D., Samuel, D., Miller, J. D., Few, L. R., \& Widiger, T. A. (2013). Development of a short form of the elemental psychopathy assessment. Assessment, 20, 659-669. https://doi.org/10.1177/1073191113502072.

McGinley, M., \& Carlo, G. (2006). Two sides of the same coin? The relations between prosocial and physically aggressive behaviors. Journal of Youth and Adolescence, 36, 337-349. https://doi.org/10.1007/s10964-006-9095-9.

Miller, J. D., \& Lynam, D. R. (2012). An examination of the psychopathic personality inventory's nomological network: A meta-analytic review. Personality Disorders: Theory, Research, and Treatment, 3, 305-326. https://doi.org/10.1037/a0024567.

Mullins-Sweatt, S. N., Glover, N. G., Derefinko, K. J., Miller, J. D., \& Widiger, T. A. (2010). The search for the successful psychopath. Journal of Research in Personality, 44, 554-558. https://doi.org/10.1016/j.jrp.2010.05.010.

Ray, J. V., Weir, J. W., Poythress, N. G., \& Rickelm, A. (2011). Correspondence between the Psychopathic Personality Inventory and the Psychopathic Personality InventoryRevised: A look at self-reported personality traits. Criminal Justice and Behavior, 38, 375-385. https://doi.org/10.1177/0093854811398178.

Schwab-Stone, M., Chen, C., Greenberger, E., Silver, D., \& Voyce, C. (1999). No safe haven II: The effects of violence exposure on urban youth. Journal of the American Academy of Child and Adolescent Psychiatry, 38, 359-367. https://doi.org/10.1097/00004583199904000-00007.

Sellbom, M., Lilienfeld, S. O., Fowler, K. A., \& McCrary, K. L. (2018). The self- report assessment of psychopathy: Challenges, pitfalls, and promises. In C. J. Patrick (Ed.), Handbook of psychopathy (pp. 211-258). New York: Guilford Press.

Somma, A., Andershed, H., Borroni, S., Salekin, R. T., \& Fossati, A. (2018). Psychopathic personality traits in relation to self-report delinquency in adolescence: Should we mind 
about interaction effects. Journal of Psychopathology and Behavioral Assessment. Advance online publication.

Steinert, S. W., Lishner, D. A., Vitacco, M. J., \& Hong, P. Y. (2017). Conceptualizing successful psychopathy: An elaboration of the moderated-expression model. Aggression and Violent Behavior, 36, 44-51. https://doi.org/10.1016/j.avb.2017.07.005.

Twenge, J. M., \& Foster, J. D. (2008). Mapping the scale of the narcissism epidemic: Increases in narcissism 2002-2007 within ethnic groups. Journal of Research in Personality, 42, 1619-1622. https://doi.org/10.1016/j.jrp.2008.06.014.

Verona, E., Sprague, J., \& Javdani, S. (2012). Gender and factor-level interactions in psychopathy: Implications for self-directed violence risk and borderline personality disorder symptoms. Personality Disorders: Theory, Research, and Treatment, 3, 247262. https://doi.org/10.1037/a0025945.

White, B. A. (2014). Who cares when nobody is watching? Psychopathic traits and empathy in prosocial behaviors. Personality and Individual Differences, 56, 116-121. https://doi.org/10.1016/j.paid.2013.08.033. 
Table 1 Cluster analysis based on psychopathic and adaptive psychopathic traits scores. Cluster comparison using ANOVA and post-hoc tests.

\begin{tabular}{|c|c|c|c|c|c|c|c|c|c|}
\hline & \multirow{2}{*}{$\begin{array}{l}\text { Sample } \\
\begin{array}{l}N=2291 \\
M(S D)\end{array}\end{array}$} & \multirow[t]{2}{*}{$\alpha$} & \multirow[t]{2}{*}{ Range } & \multicolumn{6}{|l|}{ Cluster $M(S D)$} \\
\hline & & & & $\begin{array}{l}\mathrm{NP} \\
n=568(25 \%)\end{array}$ & $\begin{array}{l}\mathrm{LT} \\
n=603(26 \%)\end{array}$ & $\begin{array}{l}\text { AP } \\
n=678(30 \%)\end{array}$ & $\begin{array}{l}\text { HT } \\
n=442(19 \%)\end{array}$ & $F$ & $\begin{array}{l}\text { Significant } \\
\text { comparisons }\end{array}$ \\
\hline Psychopathic traits & $197.53(16.49)$ & 0.67 & $153-272$ & $205.95(8.57)$ & $180.40(8.09)$ & $192.23(8.05)$ & $219.50(11.40)$ & $1843^{*}$ & $\mathrm{HT}>\mathrm{NP}>\mathrm{AP}>\mathrm{LT}$ \\
\hline Adaptive psychopathic traits & $139.60(21.63)$ & 0.86 & $71-224$ & $123.97(13.34)$ & $122.10(13.31)$ & $153.53(11.14)$ & $162.19(15.04)$ & $1325.40^{*}$ & $\mathrm{HT}>\mathrm{AP}>\mathrm{NP}>\mathrm{LT}$ \\
\hline Antisocial behavior & $19.98(14.21)$ & 0.83 & $0-120$ & $24.67(14.86)$ & $14.24(9.91)$ & $15.70(10.72)$ & $28.35(16.79)$ & $149.30 *$ & $\mathrm{HT}>\mathrm{NP}>\mathrm{AP}, \mathrm{LT}$ \\
\hline Prosocial behavior & $56.93(10.79)$ & 0.91 & $0-80$ & $54.80(10.07)$ & $58.30(10.12)$ & $58.67(10.19)$ & $55.14(12.58)$ & $21.14^{*}$ & AP,LT>HT,NP \\
\hline Perceived stress & $34.74(6.85)$ & 0.88 & $0-50$ & $38.11(6.49)$ & $36.70(6.06)$ & $32.02(6.23)$ & $31.96(6.40)$ & $144.90 *$ & $\mathrm{NP}, \mathrm{LT}>\mathrm{AP}, \mathrm{HT}$ \\
\hline Depressive symptoms & $9.41(5.51)$ & 0.82 & $0-27$ & $12.01(5.84)$ & $10.34(5.18)$ & $7.24(4.61)$ & $8.13(5.07)$ & $102.63 *$ & $\mathrm{NP}>\mathrm{LT}>\mathrm{HT}>\mathrm{AP}$ \\
\hline Suicidal ideation & $0.57(1.46)$ & 0.83 & $0-9$ & $0.98(1.93)$ & $0.64(1.54)$ & $0.24(0.82)$ & $0.44(1.24)$ & $29.56^{*}$ & NP>LT,HT,AP \\
\hline
\end{tabular}

Note. NP: Moderate negative psychopathic traits cluster; LT: Low traits cluster; AP: Adaptive psychopathic traits cluster; HT: High traits cluster. $* p<.05$. 


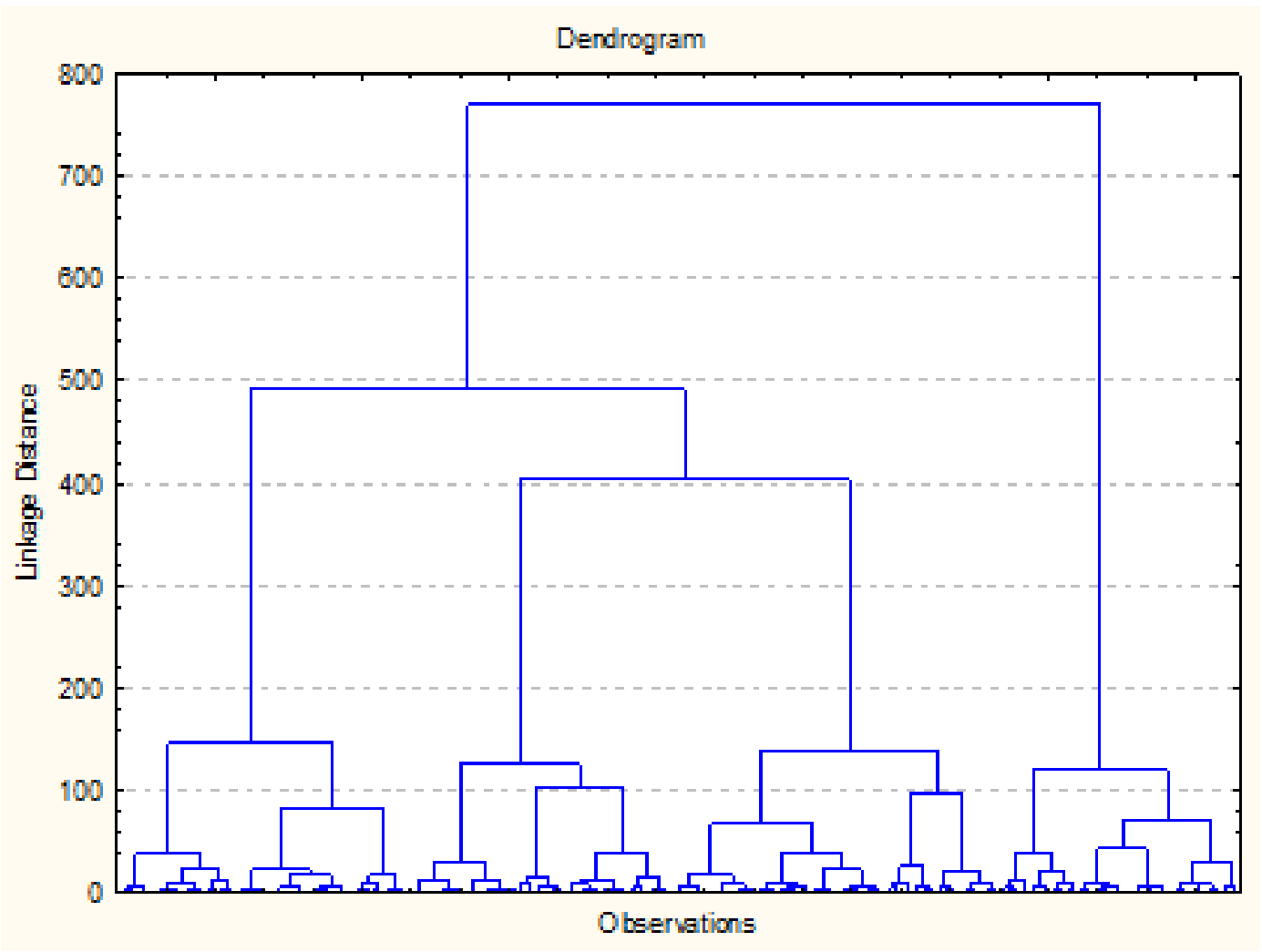

Fig. 1. Hierarchical clustering dendrogram

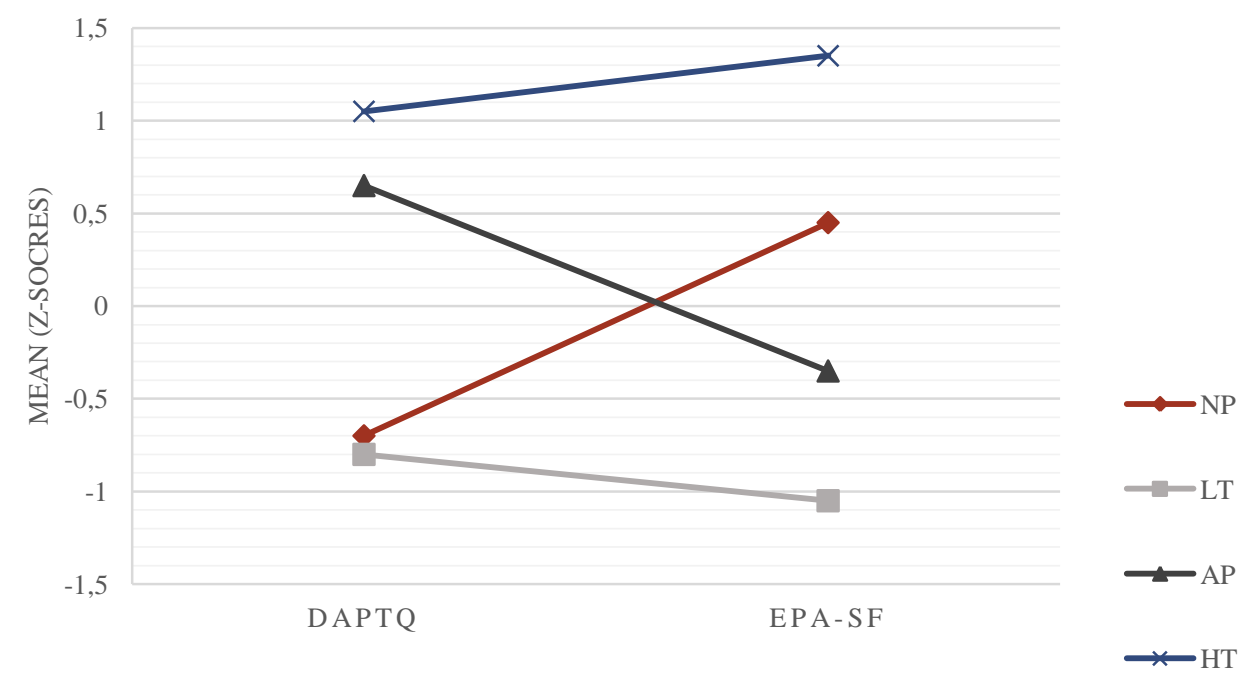

Fig. 2. Four-cluster solution (NP, LT, AP and HT) based on scores for the DAPTQ and EPASF indicated on the $x$-axis. NP: Moderate negative psychopathic traits cluster; LT: Low traits cluster; AP: Adaptive psychopathic traits cluster; HT: High traits cluster. 